\title{
O trabalho docente e o trabalho do artista: intersecções entre arte, estética e mercado na contemporaneidade
}

Teaching work and the artist's work: intersections between art, aesthetics and market in contemporary

El trabajo docente y el trabajo del artista: intersecciones entre arte, estética y mercado en la contemporaneidad 


\title{
Resumo
}

O presente artigo correlaciona arte, estética e mercado, investigando como as transformações nesta relação repercutem no ensino de arte e no trabalho docente. O objetivo é evidenciar as estratégias do capitalismo na construção de consenso, sendo uma destas estratégias o apagamento da especificidade da arte, de modo promover sua indissociabilidade com o trabalho humano. A pesquisa reitera a essência das relações e de produção de mais-valor a partir dos fundamentos do materialismo histórico-dialético e assinala a tomada de consciência teórica como pressuposto para a fruição estética, valorizando o conhecimento artístico como fundamental nas realizações humanas. A abordagem metodológica parte da análise de estudos bibliográficos, evidenciando como o desvelamento da correlação entre os campos implica em ganho interpretativo na leitura da realidade e seus desdobramentos.

Palavras-chave: Trabalho docente. Ensino de arte. Arte. Estética. Mercado de arte.

\begin{abstract}
This article correlates art, aesthetics and market, investigating how the changes in this relationship affect art education and teaching work. The objective is to highlight the strategies of capitalism in the construction of consensus, one of these strategies being the erasure of the specificity of art, in order to promote its insepa-rability from human work. The research reiterates the essence of relations and the production of more-value from the principles of historical-dialectical materialism and marks the theoretical awareness as a prerequisite for aesthetic fruition, valuing artistic knowledge as fundamental to human achievements. The methodologi-cal approach is based on the analysis of bibliographic studies, showing how the unveiling of the correlation between the areas implies an interpretive gain in the reading of reality and its consequences.
\end{abstract}

Keywords: Teaching work. Art education. Art. Aesthetics. Art market.

1 Doutoranda em Artes Visuais pelo PPGAV/UDESC, professora no PROF-ARTES da UDESC e na rede pública de ensino. Membro do Observatório da Formação de Professores de Artes Visuais. Lattes: http://lattes.cnpq. br/8363235165954192. ORCID: https://orcid.org/0000-0003-3078-8401. E-mail: pri.anversa@gmail.com.

2 Doutora em Artes Visuais pelo PPGAV/UDESC, professora do IFSC e do mestrado profissional PROF-ARTES/UDESC. Membro do Observatório da Formação de Professores de Artes Visuais. http://lattes.cnpq. br/7690907623919466. ORCID: https://orcid.org/0000-0001-9478-5475. E-mail: giovana.bianca@ifsc.edu.br. 


\section{Resumen}

Este artículo correlaciona arte, estética y mercado, investigando cómo los cambios en esta rela-ción afectan la educación artística y el trabajo docente. El objetivo es resaltar las estrategias del capitalis-mo en la construcción de consensos, siendo una de estas estrategias el borrado de la especificidad del arte, para promover su inseparabilidad del trabajo humano. La investigación reitera la esencia de las rela-ciones y la producción de plusvalor desde los cimientos del materialismo histórico-dialéctico y señala la conciencia teórica como requisito previo para la fruición estética, valorando el conocimiento artístico como fundamental para los logros humanos. El enfoque metodológico se basa en el análisis de estudios biblio-gráficos, mostrando cómo la develación de la correlación entre los campos implica una conquista interpre-tativa en la lectura de la realidad y sus consecuencias.

Palabras clave: Trabajo docente. Educación artística. Arte. Estético. Mercado del arte. 


\section{Introdução}

Este estudo tem por intuito apresentar elementos estruturais que repercutem no trabalho dos professores de arte visando compreender sua dinâmica na atualidade. Para tanto, se faz necessário entender como este se conecta com o sistema econômico e com as manifestações culturais. Logo, a arte e seu ensino são abordados a partir da premissa marxiana de trabalho. O tópico Notas sobre a historicidade do sistema de arte e seu ensino aborda um dos pontos essenciais à discussão sobre a arte no capitalismo: as origens das ideias estéticas brasileiras e o ensino de arte no Brasil, pelo prisma de Reis (2007) e Reis e Requião (2013). O tópico seguinte, intitulado As origens da arte e a gênese da práxis, apresenta o fazer artístico enquanto trabalho, refletindo sobre as questões estéticas neste processo por meio dos apontamentos de Vázquez (2010), enquanto o terceiro tópico, Arte, mercado e trabalho, problematiza o sistema de arte no capitalismo e seus reflexos na construção de um novo modelo de trabalhador a partir do conceito de celebridade (QUEMIN, 2013). Por fim, o quarto e último tópico, Meandros da docência, coloca em evidência as novas tarefas atribuídas aos professores e professoras de arte, buscando estabelecer um comparativo entre o trabalho artístico e o trabalho docente à luz do capitalismo cultural.

A análise é empreendida pela perspectiva marxiana através da ideia de que a cultura não é uma esfera onde se nega os efeitos do capital ou se refugia dele, mas sua mais evidente expressão. Consonante a esta asserção, parte do pressuposto que o capitalismo conta com uma lógica cultural voltada para o consumo, desde o consumo de massa àquilo que se convencionou chamar de alta cultura (JAMESON, 2001). Reconhecer tal lógica implica compreender que nos constituímos como ser social sob a lógica do capital, seres que vivem as contradições desse sistema.

A partir da explanação sobre como se constitui o ser social e suas relações de trabalho e emancipação humana, o texto evidencia a atual submersão aos consensos e contraria a ideia que se espraia no capitalismo, qual seja, a crença de que a educação é, por si só, um ato emancipatório.

Há infinitos discursos que colocam a educação neste âmbito, classificam-na como redentora. Parte significativa deste consenso é alimentado por ideologias de matizes pós-modernas que caracterizam artistas e aprendizes enquanto sujeitos desencarnados das relações sociais de produção (REIS; REQUIÃO, 2013). Ocorre, porém, que a arte e seu ensino não podem ser subsumidos a uma esfera apartada da realidade. Por esta razão sublinha-se a necessidade de debater a arte entendendo sua gênese enquanto fruto do trabalho humano, peça chave nas discussões sobre educação, estética e formação humana. 


\section{Notas sobre a historicidade do sistema de arte e seu ensino}

A despeito da necessidade de discutir e compreender a natureza do tema deste tópico e sua história, faz-se necessário frisar que embora as pautas aparentem ter avançado quanto à inserção da arte no currículo escolar, sua existência é frágil, especialmente porque a conquista da arte no currículo não se vincula diretamente ao aprofundamento do debate em torno das diferentes concepções de arte e de educação, tampouco significa a permanência da disciplina no local ao qual se encontra atualmente no currículo.

A educação estética foi engendrada pelo projeto teleológico-educativo burguês da arte no Brasil, projeto que fundiu intelectuais modernistas e empresários em meados da década de 1930 que atuaram no cenário cultural brasileiro por meio de diferentes ações: implementação do Canto Orfeônico nas escolas, Educação Musical e Artística para a formação de professores, criação do INCE (Instituto Nacional do Cinema Educativo), oficialização do Salão Nacional de Belas-Artes, surgimento da Escolinha de Arte do Brasil sob influência de Mário Pedrosa em fusão às ideias de Herbert Head e envolvimento da intelectualidade burguesa militante nos debates entre arte e educação (REIS; REQUIÃO, 2013).

Neste processo "o capitalismo brasileiro reestruturou produtivamente a área cultural justapondo e sobrepondo elos das artes com cadeias produtivas industriais e mercantis" (REIS; REQUIÃO, 2013, p. 11). A televisão sofisticou essa cadeia, influenciando significativamente as relações sociais de produção artística e o perfil da formação técnico-profissional, movendo a cultura para a área dos negócios e criando dependência cada vez maior de investimentos públicos e privados ou de parcerias em ambos os setores. Estas modificações impactaram o ensino de arte, cuja sistematização de ideias deriva de uma revisão da arte a partir de Hegel, na medida em que este trouxe o corpus teórico da história social da arte através do método dialético de abordagem da realidade, rompendo com a tradição kantiana e empiricista de sua época (REIS, 2007).

Conforme Reis (2007), a intenção da teleologia de Hegel visava educar a coletividade humana para as Belas-Artes, formando público para o calendário oficial da cultura artística promovido pelo Estado, transformando de forma avassaladora a mudança de gosto (dominado até então pela estética clerical e aristocrática), visando o processo de desenvolvimento das forças produtivas, do progresso técnico face aos novos materiais que resultaram na separação da arte enquanto processo industrial versus a experimentação estética formal pela autonomia da linguagem visual. Com efeito, a ideologia estética hegeliana apresentada como expressão concreta da realidade, não se constituiu enquanto totalidade apenas por se valer do método dialético. Ao contrário, caracterizou-se como idealização determinada pelo aparato ideológico que não deu conta de superar as contradições internas do sistema criado, o qual descartou o modo como os homens historicamente produzem a vida em sociedade como possibilidade de análise. 
Vázquez (2010), por sua vez, a partir dos Manuscritos econômicos-filosóficos de 1844 de Marx, estruturou o entendimento do homem como produtor de objetos. Nas palavras do autor, o homem cria objetos que satisfazem suas necessidades, os quais existem por e para ele. Esta concepção possibilitou entender a produção de objetos e de arte que noutros tempos estavam relacionados a teorias idealistas as quais deixaram lacunas sobre a compreensão dos fenômenos basilares da arte, tema a ser abordado no tópico a seguir.

\section{As origens da arte e a gênese da práxis}

A contribuição de Marx à Estética incide em ter demonstrado que o estético se forjou histórica e socialmente no processo de transformação da natureza e de criação de um mundo de objetos humanos. Para Marx, a origem da arte deriva do trabalho ${ }^{3}$, noção que desmantelou a oposição radical da estética idealista alemã que concebe o trabalho como rigorosa necessidade vital, composto por dor e sofrimento em contraponto à atividade artística, caracterizada pela expressão das forças livres e criadoras do homem, por alegria e prazer.

Com base na tese marxiana, Vázquez (2010) refuta esse conceito, elucidando os produtos do trabalho enquanto criações que satisfazem determinada necessidade humana, e valem justamente pela capacidade de satisfazê-la (função prático-utilitária) e por objetivar as forças essenciais do ser humano (função espiritual). Entre essas duas funções do produto há tensão e conflito, no entanto uma não anula a outra, porque ao criar objetos humanizados ao transformar a natureza, o ser humano supera o próprio limite prático-utilitário do trabalho, passando, assim, do útil ao estético, do trabalho à arte.

O ponto de partida de Marx, presente também em Kosik (2002), pressupõe que o ser humano, ao se apropriar da natureza, o faz impregnando-a e aos seus sentidos de humanidade, tornando-os teoréticos ${ }^{4}$. Vázquez (2010) sublinha que a criação artística leva ao conhecimento da essência dos fenômenos, enriquecendo o ser humano com novos conhecimentos, evidenciando que a tomada de consciência teórica se deve à fruição estética, valorizando o conhecimento artístico como fundamental nas realizações humanas. A sensibilidade é forjada no e pelo trabalho criativo, resultado do esforço do corpo trabalhador. Tanto a arte quanto o trabalho são criações de realidade em que plasmam finalidades humanas prático-utilitárias e espirituais ${ }^{5}$. A utilidade da obra não reside na capacidade de satisfazer uma necessidade material determinada, mas "a necessidade geral que o homem sente de humanizar tudo

3 É fundamental a compreensão de trabalho não como produção de mercadoria, mas como ação humana que transforma a natureza para a satisfação de necessidades.

4 A este respeito ver Kosik (2002).

5 A utilidade espiritual em Marx refere-se à capacidade de expressar o humano em toda sua plenitude. 
quanto toca, de afirmar sua essência e de se reconhecer no mundo objetivo criado por ele". (VÁZQUEZ, 2010, p. 62). É a capacidade de criar, de modificar a natureza, portanto, o estatuto ontológico da arte.

Por este ângulo, arte e trabalho não se diferenciam como supunham os estetas idealistas. Ao historicizar o trabalho e a arte em suas primeiras experiências na pré-história, é possível que os objetos de arte derivam da produtividade do trabalho humano, pois foi necessário haver excedente (objetos inúteis materialmente), para que, ao estarem libertos dessa função, passassem a ter função estética (ou espiritual). Por isso o trabalho é a condição necessária ao aparecimento da arte e da relação estética do homem com seus produtos.

É fundamental ter em mente que o ser humano passou do trabalho para a arte, e que a arte, mesmo sucumbindo à lógica do capital - ponto que será retomado adiante -, é atividade humana tal qual o trabalho, não é inata, não é ócio, não é dom, nem prazer, mas uma forma de refletir a realidade e de, portanto, criar realidades. Abundam situações em que a arte na escola ainda seja encarada como ação espontânea e geradora de prazer, com uma finalidade que escapa à lógica capitalista, pois não é associada ao trabalho na medida em que é concebida enquanto atividade não produtiva. Igualmente, o fetiche que envolve a imagem do artista e sua atividade profissional oculta suas necessidades humanas e as condições reais de produção, em que dom e talento configuram o encobertamento dos processos concretos da produção artística desde a aprendizagem até o consumo da mercadoria arte pelo público.

É de domínio público a noção do senso comum que associa o trabalho artístico, ao lazer, ao entretenimento e ao ócio, e que a mesma se estende a quem dele usufrui e, principalmente, a quem produz arte. É sabido que tal conceito de atividade artística como não produtiva (ou que não gera renda) apenas reforça a ideia do senso comum de que o trabalho de arte se funda numa espécie de "inspiração divina" ou "dom" velando a sua materialidade concreta e alimentando a dissociação entre o trabalho de arte e o trabalho em geral. (REIS; REQUIÃO, 2013, p. 3).

Contrariamente, compreender o estatuto ontológico da arte permite "apreender a importância da educação estética como condição inaugural de toda a formação humana" (REIS; REQUIÃO, 2013, p. 3). No entanto, longe de encarar a arte como pressuposto à formação humana, o capital se vale de seus meios a título de manter e controlar o capital cultural da classe dominante, o que respalda na formação cultural e estética da produção de arte, do consumo e do ensino dela.

O corpo teórico da educação estética da modernidade advinda com o capitalismo em pleno século XVIII, foi mediado pelas Academias de artes em decurso das disputas políticas hegemônicas internas que atravessava a assimilação e reconhecimento dos objetos artísticos pelos colecionadores e demais agentes, numa espécie de nicho de mercado a ser consolidado. A ruptura artística no século XX levou a progressiva apropriação por parte da indústria das ideias estéticas dos artistas de 
vanguarda e à aceitação das obras pelo mercado. Neste sentido, houve então a transição do telos estético: dos estilos acadêmicos para as vanguardas (REIS; REQUIÃO, 2013). A respeito da polarização em torno da dimensão positiva e negativa da arte, cabe ressaltar que sob o capitalismo houve o agravamento dos discursos da intelectualidade burguesa, resultando nas oposições vazias como por exemplo, a noção de modernismo versus pós-modernismo, como se bastasse evidenciar uma nova prática para romper com o telos estético até então vigente.

Neste ponto, é necessário retomar o debate sobre a arte na lógica do capital deixado em aberto anteriormente. Do ponto de vista econômico, o trabalho do artista assalariado é trabalho produtivo na forma clássica de remuneração do capital: gera lucro sobre o trabalho realizado, assumindo dupla dimensão: técnico-produtivista e criativa. O trabalho artístico produz beleza, emoções, prazer, ideias, mas na medida em que é submetido à lei de produção material capitalista, é tão somente uma atividade produtiva. Noutras épocas o trabalho artístico não era produtivo no sentido capitalista, mas era remunerado: compradores desfrutavam de sua posse em troca da soma que desembolsavam, que não servia para obter novo valor superior ao que foi pago, ou seja, os produtos do artista eram vendidos diretamente ao comprador, o que, em linhas gerais, esgotava seu destino. $O$ trabalho do artista era resultado de trabalho concreto, qualitativo, com valor de uso específico, em que a relação produto versus possuidor não passava pelo mercado, não era, portanto, mercadoria. (REIS; REQUIÃO, 2013).

Para o capitalismo, o trabalho artístico que se esgota em seu valor de uso não produzindo excedente de valor (mais-valia) é trabalho improdutivo, pois ainda que enriqueça espiritualmente tanto o produtor quanto o consumidor, precisa enriquecer o capital. Conforme assinala Marx (1980) o que classifica um trabalho como produtivo ou improdutivo não é o caráter especial do trabalho, porque o mesmo trabalho pode ser produtivo se um capitalista ou um produtor o compra para dele obter lucro, ou improdutivo, se comprado por um consumidor, isto é, quem nele invista parte de sua renda a fim de consumir seu valor de uso. Assim, é importante sublinhar que no capitalismo, a dimensão criativa molda-se aos critérios produtivistas na medida em que há controle do fator criativo, ajustando-o.

A ênfase neste debate reflete não sobre a produção artística enquadrada como trabalho produtivo como explicitado acima, mas à que se refere ao artista não assalariado (o que não remunera o capital) e, portanto, classificado como trabalho improdutivo na medida em que não gera mais-valia. Para o capitalismo, o trabalho do artista não assalariado (autônomo) é trabalho excedente que garante estabilidade ao sistema na medida em que assegura a acumulação capitalista.

O artista autônomo depende então cada vez mais dos que controlam o meio de circulação da arte, acarretando o controle do fator criativo e, consequentemente, no conjunto das relações de sua produção. Nada escapa à vigília do capital, o que confere ainda mais a responsabilidade do pesquisador em compreender a conjuntura econômica, educacional e artística nunca de forma isolada sem examinar a 
totalidade das relações socioculturais nos variados contextos. Tal assertiva reitera a análise do processo de produção capitalista na ótica de Jameson (2001), autor que aponta para as transformações culturais como elemento não de oposição (ou distinção) ao capital, mas pelo contrário, o legitimam. Pensar o econômico e o estético como esferas distintas é impossível na era pós-moderna.

Em relação ao trabalho docente, há uma disseminação relativamente consensuada sobre suas características. Espera-se uma performance profissional que envolva domínio dos conteúdos, desenvolvimento de um bom relacionamento interpessoal, disponibilidade e acessibilidade, entre tantas outras coisas. No tópico a seguir abordaremos pontos em comum entre as duas carreiras, a do artista e a do professor, no intuito de enxergá-las como dois lados de uma mesma moeda: trabalhadores que vivem o capitalismo cultural tentando lidar com um mundo estetizado. Os dois vivendo de seu trabalho em um mundo instável e sendo impulsionados a assimilar novas funções. Em ambos os casos, o mérito ou demérito profissional passam a ser encarados como uma questão subjetiva atrelada ao desempenho pessoal e às escolhas de cada indivíduo.

\section{Arte, mercado e trabalho}

Pensar as dimensões do trabalho na contemporaneidade implica em reconhecer a influência avassaladora do capitalismo. Barbosa (2006, p. 39), ao discutir a política de desempenho nas sociedades modernas, ressalta que a questão do mérito é um dos pilares fundantes da sociedade atual, tratando-se o sucesso mais de um produto pessoal que social. Desta forma, o conjunto de aptidões de cada indivíduo é apresentado como um mecanismo socialmente legítimo que dá o direito à sociedade de avaliar, julgar, classificar, premiar e punir. É a crença no desempenho e na igualdade de oportunidades que permite ao capitalismo classificar cada sujeito como bem ou malsucedido; aqueles excepcionalmente bem sucedidos podem, inclusive, alcançar o status de celebridades. Ser categorizado como celebridade equivale a um passaporte de consagração para tratamentos diferenciados e concessão de benefícios muito acima da média.

O conceito de celebridade envolve reconhecimento midiático, cuja personificação dos atributos simbólicos sacraliza a pessoa midiática e a converte em mercadoria simbólica. O sujeito celebridade vale pela sua imagem e não, necessariamente, pela sua produção. A fabricação de celebridades pode ser considerada indissociável da produção do fetiche cultural mercadológico, uma vez que a celebridade está exposta constantemente à comentários valorativos. Para Khel (2004, p. 82), o indivíduo celebridade é um fetichista, visto que transforma sua produção em fetiche, e, ao mesmo tempo, se configura como o próprio fetiche, pois "vende" a própria imagem.

O conceito de "fetichismo da mercadoria" foi cunhado por Karl Marx em 0 Capital para se referir aos estratagemas que as mercadorias possuem para, no capi- 
talismo, ocultar as relações sociais de exploração do trabalho. Adorno e Horkheimer se dedicaram ao estudo do fetichismo a partir da indústria cultural. O termo "indústria" se relaciona à infraestrutura e o termo "cultural" à superestrutura. Na superestrutura a aparência não corresponde apenas ao ocultamento da essência, mas à própria essência. A indústria cultural, conforme Adorno e Horkheimer (1985), está atrelada à exploração econômica e volta-se à geração de lucro e à adesão do público ao sistema capitalista. Nesta acepção, o fetichismo da mercadoria cultural evidencia duas problemáticas: o valor de uso (ou valor de troca) que oculta as relações sociais por uma hipervalorização do objeto e a coisificação dos sujeitos. A ideia de "fetichismo da mercadoria cultural" está coadunada com a noção de que o valor de troca reside justamente na suposta ausência de valor de uso, sendo que "o sujeito se torna fungível tal como a mercadoria o é" (SILVA, 2010, p. 378). São por estas razões, e crentes na autonomia da arte, que Adorno e Horkheimer (1985) sugerem a impossibilidade de a arte autêntica ser subjugada pela indústria cultural.

O posicionamento de Jameson (2006) difere de Adorno e Horkheimer, pois para ele o emaranhamento entre arte e cultura alia-se à dilatação desses na economia. Para Jameson a união entre a produção estética e a produção de mercadorias não é simplesmente a dissolução da cultura na esfera da produção material, mas a neutralização do conteúdo crítico da arte. Jameson rejeita padrões fixos para definir o que seja a "grande arte". A arte, no atual estágio do capitalismo, parece valer menos que os artistas que a produzem, pois estes atingiram o status de celebridades extensoras de tudo o que possa ser vendável. As vendas, de toda e qualquer mercadoria, estão atreladas a diversos mecanismos de divulgação como, por exemplo as listas hierárquicas que induzem o público a diferenciar a "boa" mercadoria daquela "nem tão boa".

Praticamente tudo na sociedade contemporânea está sujeito à aferição de valor quantitativo e consequente escalonamento em rankings. Há listas de desempenhos variados e a disseminação dessas pela imprensa assume, cada vez mais, papel importante na popularidade profissional e social das pessoas nelas envolvidas, assim como na vida das pessoas não mencionadas. Figurar o ranking dos cantores cuja música foi a mais tocada pode não representar uma situação rigorosamente comprovável, mas amplia as chances de que isto venha de fato a acontecer em razão da publicação da lista. Desta feita, o aspecto performativo veiculado na mídia está muito mais ligado à formação de posicionamentos do que à notícia.

De acordo com a pesquisa de Quemin, ao analisar a dinâmica de classificação dos rankings, é possível observar que os Estados Unidos e a Alemanha detêm mais da metade da concentração dos artistas considerados bem-sucedidos. O Reino Unido, a Suiça e a França seguem respectivamente na terceira, quarta e quinta posição. Estes cinco países respondem sozinhos por $80 \%$ do peso dos artistas com maior visibilidade. Na pesquisa, Quemin procura demonstrar a fragilidade do discurso amplamente alardeado de que estaríamos vivendo em tempos de globalização cultural. 
O mundo da arte contemporânea internacional continua a ser altamente territorializado e hierarquizado no que diz respeito aos países, segundo configurações que podem ser encontradas em diferentes níveis e segmentos. [...] Em termos de consagração artística, a autoridade de certificação ainda está concentrada nas mãos de um pequeno número de instituições e de agentes que são quase todos ocidentais e que elegem sempre outros artistas ocidentais antes de escolher aqueles pertencentes a outras partes do globo. (QUEMIN; VILLAS BÔAS, 2016).

A disseminação da ideia de que a arte produzida em determinados polos geográficos tenha maior destaque mercadológico devido a um aspecto mais vanguardista que a arte produzida em outras partes do globo, está calcada em interesses ideológicos e convive com a falsa impressão de um esforço em prol da globalização democrática da arte. Para Jameson (2001), o discurso que vincula a globalização à ideia de amálgama cultural é uma estratégia política, uma vez que este discurso não considera a articulação entre os níveis tecnológico, político, cultural, econômico e social, processo fundamental em se tratando de uma política de resistência. Uma análise rigorosa evidenciará que a globalização é um engodo, principalmente no quesito cultura, onde os efeitos são devastadores. Jameson lembra que desde o final da 2 ${ }^{\mathrm{a}}$ Guerra, os Estados Unidos mantém esforços para garantir a exibição de seus filmes nos mercados estrangeiros, insistindo na derrubada das políticas de protecionismo cultural e revogando leis locais.

Por que é tão importante estabelecer e evidenciar quem são os melhores? A quem, ou a quê, interessam tais classificações? Para Stallabrass (2014), assim como para Jameson (2006) e Quemin (2013), os artistas celebridade dão prova da influência do capitalismo no mundo da arte. Acerca de tal fenômeno - que Sttalabrass chama de "cultura de superfície trivial" (2014, p. 152) -, as questões que movem sua pesquisa se assemelham às preocupações que fundamentam a pesquisa de Quemin. Sttalabrass é motivado pela atenção que a arte contemporânea tem dado à exploração e à opressão, assim como a todo tipo de desigualdades. Na esteira do pensamento jamesoniano, Stallabrass busca respostas na ênfase da arte ao ativismo popular transfigurado em populismo, entendido como uma recusa à complexidade para atingir o indivíduo comum, novo consumidor de arte.

Aproximar o fazer artístico ao fazer populista, ranquear celebridades e adequar o produto artístico ao novo consumidor são estratégias do capitalismo cultural que impactam diretamente no trabalho do artista. Além da questão geográfica, há um modelo pré-concebido para figurar na lista de artista celebridade que induz a um novo modelo de trabalhador: um sujeito autônomo que não separa atividade laboral e vida pessoal. Muito embora essa discussão esteja atrelada à atividade artística e o produto dessa atividade, ou seja, à arte, interessa, no presente texto, apontar as direções que o trabalho docente pode empregar ao assumir a existência das contradições, pautando-as na relação entre as determinações. Abordaremos os desdobramentos dessa relação no tópico a seguir. 


\section{Meandros da docência}

No exercício do trabalho docente, o que parece estar em foco no senso comum são as expectativas sociais em relação ao seu trabalho. Poucos ousam avaliar um artista, por exemplo, como 'não-bom' a partir de sua performance técnica; para a maioria das pessoas parece muito mais seguro socialmente avaliar um artista como profissional bem ou mal sucedido de acordo com sua inserção no mercado. Em contrapartida, o julgamento sobre a atividade profissional docente é comum. Para Feitoza, Cornelsen e Valente (2007), a disseminação social dos critérios para classificar e julgar o trabalho dos professores envolve, entre outras coisas, o próprio contexto formativo que veicula ideias e valores entre os integrantes da sua comunidade.

Diferentemente da ênfase dada ao artista em relação à capilaridade e retribuição financeira por sua produção, o profissional da educação é abertamente julgado por sua competência. Conforme sugerem Shiroma e Evangelista (2003, p. 81), "um fantasma ronda o professor: a mística da competência". O discurso da competência exige a capacitação constante e o comprometimento pessoal diante dos resultados pífios do sistema educacional. Cada professor passa a ser diretamente responsável pelo desempenho de seus alunos em testes nacionais e internacionais, invertendo a lógica interna, como se tais resultados não fossem fruto do próprio sistema.

No senso comum, o discurso acerca do trabalho docente está calcado na certeza de um cotidiano sofrido, repleto de percalços e desgaste físico. Fica subentendido que cabe às pessoas que optarem por esta profissão, enfrentar esta realidade com dignidade, em detrimento das condições adversas.

Se antes o reconhecimento público estava relacionado a um grupo seleto de sujeitos, cujo prévio trabalho intenso fosse considerado dificilmente superável (embora se saiba que condições sociais tenham sido propícias para o feito), atualmente a fama tende a estar mais diretamente conectada a um impulsionamento digital que a antecede. Nesta perspectiva, alguns professores mais familiarizados com as ferramentas digitais têm galgado seu espaço rumo ao 'estrelato', embora mais modestamente que os artistas. Goulart (2014), ao analisar o desempenho dos docentes mais ativos nas mídias sociais, opta por elencar as consequências positivas resultantes da desenvoltura dos docentes junto às mídias, enumerando ganhos pedagógicos significativos:

- Comunicação: quem usa mídias sociais e o WhatsApp tende a se comunicar com maior agilidade com seus alunos;

- Criação: ferramentas on-line permitem o registro de documentos compartilhados, sendo mais fácil sustentar processos criativos, minimizando a preocupação com a autoria; 
- Contribuição: usando mídias colaborativas com papéis de usuários definidos é possível compartilhar tarefas e criar espaços de armazenagem comuns que sustentam o processo de contribuição entre várias pessoas;

- Compartilhamento: a regra é dividir o que se tem: fóruns se transformam em instrumentos de construção de conhecimentos e agregam informações de origens diversas;

- Cooperação: ampliam-se as oportunidades de ações realizadas em conjunto, valorizadas e encorajadas. No trabalho do professor conectado, o planejamento passa a ser mais elaborado;

- Coordenação: o professor conectado pode fazer uso de ferramentas digitais para coordenar grupos e gerenciar tarefas com maior eficácia.

Todas estas características assumem, num primeiro momento, uma aura de sedução e possuem, inequivocamente, suas vantagens. Trata-se de um sujeito onipresente que, novamente, assume o controle tendo não somente o que dizer, mas onde dizer. Este novo professor ativo nas mídias sociais, dissemina opiniões e induz reflexões por meio de vídeos no YouTube, assume sua humanidade ao postar fotos de momentos cotidianos, alerta sobre os melhores filmes em cartaz e propaga recomendações sobre bons documentários, shows e peças teatrais. Conforme Lipovetsky e Serroy (2014, p. 460), trata-se da inserção da educação na "cultura dos prazeres imediatos". Pouco a pouco a educação alinha-se à cultura da felicidade compartilhada, onde um desejo partilhado por muitos passa a ser entendido como legítimo. O problema, na visão de Lipovetsky, é que o discurso anunciado como 'compartilhamento' se transforma facilmente em competição, evidenciando um ideal de sujeito: multitarefas, alta performance, portador de veleidades estéticas cuja vida plena e feliz antagoniza com vidas 'sem graça':

Um número crescente de indivíduos testemunha um gosto gratuito pela criação ou expressão estética. [...] cada vez mais os indivíduos se querem criadores, tocam música, fazem fotografia, praticam a dança, se entregam à pintura, participam num coro, fazem cursos de teatro, exercem a gastronomia, escrevem memórias, têm um blogue. (LIPOVETSKY; SERROY, 2014. p. 472).

Em certa medida, a vida high-tech acelera a tendência à prática artística e mobiliza o desejo para a realização de algo pessoal e totalmente novo que atenda os interesses subjetivos de cada um. Não se trata de entender o mundo por meio da arte, trata-se de se colocar no mundo de maneira performática e singular. $\mathrm{O}$ professor conectado pode chegar a ser um professor celebridade. Para isso ele precisar ser singular, excepcional, de forma que sua vida e seu trabalho se confundam de tal 
maneira que pareça impossível separar uma coisa da outra. No fundo, o professor celebridade é mais um, entre tantos trabalhadores, buscando a sobrevivência social de sua profissão. Suas horas de preparação e formação não incluíram glamour, nem tampouco foram abreviadas em razão do uso de dispositivos eletrônicos, porém sua adaptação ao meio digital o tornou atrativo para o capitalismo cultural.

Não se pode dizer que a eleição de celebridades seja algo tão novo. Guy Debord (1997) nos anos 60, já previa o alastramento do fenômeno para as mais diversas áreas, alertando sobre a forma como a sociedade passou a se relacionar com as imagens construídas e alimentadas pelas mídias sociais. De alguma forma, a representação de algo, o que este algo parece ser, passou a ser mais importante do que de fato este algo é. O capitalismo cultural estetiza tudo, fetichiza tudo, apresentando um mundo passível ao consumo gourmetizado ${ }^{6}$.

Curioso com a banalização do termo gourmet, Van Deursen (2014) resgatou quantas vezes o termo apareceu no jornal O estado de São Paulo: uma vez em 1901; 10 ocorrências até os anos 70; cerca de 80 aparições por ano entre os anos 80 e 90; 1.144 vezes em 2005; e surpreendentes 14 vezes por dia em 2010. Um dos pressupostos para a gourmetização de algo é evidenciar os problemas existentes na sua forma popular de apresentação.

No que se refere à educação, a gourmetização teve início muito antes do termo virar modismo, haja vista a precarização do serviço público para o enaltecimento das redes privadas. Professores de cursinhos pré-vestibulares e preparatórios para o ENEM ganham algum reconhecimento social ao trabalharem numa perspectiva que preconiza a aprendizagem rápida e pragmática, visando o acesso do aluno a um ritual de passagem, qual seja, uma vaga nos cursos de graduação. Nesta perspectiva, ser um professor que intui quais os prováveis conteúdos que estarão presentes nas provas de seleção ou anteveja possíveis temas de redação pode ser uma grande jogada de marketing profissional. O acesso a tais informações funciona como um plus, um diferencial que confere ao professor certo prestígio e respaldo social.

6 O termo francês gourmet, que ganhou popularidade no mercado gastronômico para indicar um produto refinado (geleias gourmet, brigadeiros gourmet, pipocas gourmet), foi incorporado aos mais diversos setores de consumo. 


\section{Considerações finais}

Entender o mundo contemporâneo e suas relações na esfera cultural e educacional sem adentrar nos debates sobre capital financeiro é um exercício vão. Neste sentido, a premissa elementar contumaz buscou clarificar as relações de produção no sistema capitalista e a perspectiva educacional contemporânea através da compreensão do trabalho artístico e docente, postulando a arte e a estética a partir das relações sociais de produção. A arte, assim como qualquer outra esfera, pode reproduzir o mesmo tipo de exclusão e dominação intrínsecos a qualquer outra mercadoria no capitalismo.

A consolidação de um ideal de arte brasileira em consonância com o mercado é parte de um projeto teleológico que alimenta a formação estética e cultural a partir do trabalho humano, verdadeira e única fonte de riqueza. Condições precarizadas de trabalho empurram artistas e professores a assumirem fazeres que legitimam os interesses do capital.

Ensinar arte requer considerar a influência do mercado na construção de valores simbólicos na contemporaneidade, uma vez que o universo de trabalho de artistas e docentes materializam as consequências desta influência. $O$ deslocamento discursivo do trabalho docente em artes somado à progressiva inserção do mercado que dita parâmetros para a arte, são aspectos de um sistema capitalista que se reproduz a partir da cooptação das manifestações culturais. A mola propulsora do capitalismo continua sendo a força de trabalho para produzir mais-valor. Num sistema capitalista o que muda ao longo do tempo é a forma como se organizam as forças produtivas. Nas relações sociais contemporâneas o capitalismo almeja trabalhadores flexíveis e dispostos se reinventar, que propagandeiem as vantagens da mobilidade social, que defendam uma carreira baseada no mérito e na crença na igualdade de oportunidades. Neste contexto, o capital almeja que se ensine arte ressaltando sua natureza flexível e popular, vinculando-a a funções sociais e mostrando como o fazer artístico como naturalmente comprometido com ideias inclusivas. 


\section{Referências}

ADORNO, T.; HORKHEIMER, M. Dialética do Esclarecimento. Tradução de Guido Antonio de Almeida. Rio de Janeiro: Zahar Editores, 1985.

BARBOSA, L. Igualdade e meritocracia: a política do desempenho nas sociedades modernas. Rio de Janeiro: Editora FGV, 2006.

DEBORD, G. A Sociedade do Espetáculo. Rio de Janeiro: Contraponto, 1997.

FEITOZA, L. A.; CORNELSEN, J. M.; VALENTE, S. M. P. (2007) - Representação do bom professor na perspectiva dos alunos de arquivologia. Perspectivas em Ciência da Informação. Vol. 12, n 2, p. 158-167.

JAMESON, F. A cultura do dinheiro: ensaios sobre a globalização. Petrópolis, RJ: Vozes, 2001.

A virada cultural: reflexões sobreo pós-moderno. Trad. Carolina Araújo. Rio de Janeiro: Civilização Brasileira, 2006.

KHEL, M. R. Fetichismo. In: BUCCl, Eugênio; KHEL, Maria Rita. Videologias. São Paulo: Boitempo, 2004.

KOSIK, K. A dialética do concreto. Rio de Janeiro: Paz e Terra, 2002.

LIPOVETSKY, G.; SERROY, J. O capitalismo estético na era da globalização, Lisboa: Edições 70, 2014.

MARX, K. Teorias da mais valia: história crítica do pensamento econômico (livro 4 de O capital). Rio de Janeiro: Civilização Brasileira, 1980.

QUEMIN, A. Les stars de l'art contemporain. Paris: CNRS Editions, 2013.

QUEMIN, A.; VILLAS BÔAS, G. Arte e vida social: pesquisas recentes no Brasil e na França. Marceille: Open Edition Press, 2016.

REIS, R. R. Entre a esperança e a realidade sobre a arte e o seu ensino. Sinais Sociais, v. 2 n5, p. 100-127. Rio de Janeiro, 2007. Disponível em: http://www.sesc. com.br/portal/publicacoes/sesc/revistas/sinaissociais/n5/n5. Acesso em 21 jan. 2020. 
REIS, R. R.; REQUIÃO, L. Para uma crítica da educação estética no Brasil. 36 Reunião Nacional da ANPEd, Goiânia, 2013. Disponível em: http://www.anped.org. br/biblioteca/item/para-uma-critica-da-educacao-estetica-no-brasil.

Acesso em 23 out. 2019.

SILVA, F. C. O Conceito de fetichismo da mercadoria cultural de T. W. Adorno e

M. Horkheimer: uma aplicação ao fetichismo marxiano. Revista Kínesis Vol. II, $\mathrm{n}^{\circ}$ 03, Abril-2010, p. 375 - 384.

SHIROMA, E. O.; EVANGELISTA, O. O fantasma ronda o professor: a mística da competência.In: MORAES, Maria Célia Marcondes de (Org.).Iluminismo às avessas: produção de conhecimento e políticas de formação docente. Rio de Janeiro:

DP\&A, 2003. p. 81-98.

STALLABRASS, J. Arte de elite em uma era de populismo. Trad. Daniela Kern.. Revista-Valise, Porto Alegre, v. 4, n. 7, ano 4, julho de 2014.

VAN DEURSEN. Tudo gourmet. Disponível em: $\underline{\text { https://super.abril.com.br/ideias/ }}$ tudo-gourmet/. Acesso em 13 set. 2018.

VÁZQUEZ, A. S. As ideias estéticas de Marx. 3. ed. São Paulo: Expressão Popular, 2010.

Submetido em 15/09/2021

Aprovado em 11/11/2021 